\title{
Kinematics and Control of a Planar Cable Robot
}

\author{
P. KAPITÁNY1 , J. LÉNÁRT ${ }^{2}$ \\ 1University of Miskolc, Faculty of Mechanical Engineering and Informatics, Robert Bosch Department of \\ Mechatronics, kapitanypalma@gmail.com \\ 2University of Miskolc, Faculty of Mechanical Engineering and Informatics, Robert Bosch Department of \\ Mechatronics, lenart.jozsef@uni-miskolc.hu
}

Abstract. This paper deals with the kinematics and control of a planar cable robot [1], which is driven by four DC motors with gear. Cable robots are frequently used e.g., for the motion of cameras in sport halls and stadiums and also in high storage logistical systems [2]. Main goal of this research work is to design and build a test bench with low budget, which can model the motion of real life cable robots.

\section{Introduction}

Cable robots are frequently used e.g., for the motion of cams in sport halls and stadiums and also in high storage logistical systems ([1], [2]). The advantage of such robots that it can move the endeffector very fast within a huge working area ([1]-[7]).

Main goal of this research work is to design and build a test bench with low budget, which can model the motions of 2D cable robots. The cables are driven by four DC motors which contain end-coders, i.e., Hall sensors. The control of rotational speed of each individual motor is based on PWM signal, which is provided by microcontroller. The path and the velocity of the end-effector are determined by kinematical equations.

The rest of the paper is organized as follows: the kinematical formulation of the cable robot is described in Section 1. The structure of the cable robot is given in Section 2. The control of the system is detailed in Section 3. Summary and concluding remarks are given in Section 4.

\section{Kinematical formulae of the cable robot}

A curve path of the end-effector is approximated by polygon as it is shown in Figure 1. It is assumed that the velocity of the end-effector along sections of the polygon is constant, which is equal to the maximum of the cable velocity provided by the DC motor at nominal rotations per minute $n_{\max }$. Therefore kinematical formulation of the cable robot is prescribed by assuming uniform $\Delta t$ time increment, while the rotation speed of the motor, i.e., the velocities of the cables are constant.

The velocities of the cables, i.e., the rotational velocity of the gear system, can be determined by the use of notations shown in Figure 1, where vectors are denoted by boldface letters. The $i^{\text {th }}$ side of the polygon given as a vector $\Delta \mathbf{r}_{\mathbf{E}, \mathbf{i}}$ 


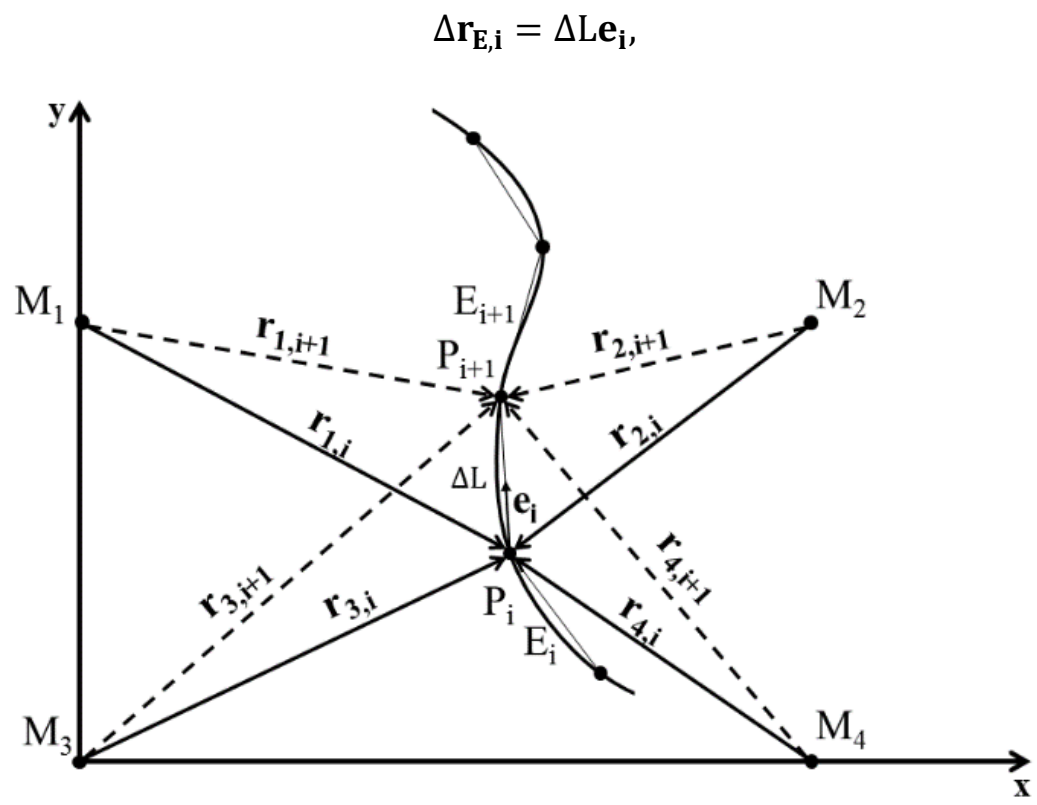

Figure 1. Mechanical model of the system

where $\Delta \mathrm{L}$ is the length of the side, $\mathbf{e}_{\mathbf{i}}$ is a unit vector.

The location vectors of the ends of the polygon sides denoted by $\mathbf{r}_{\mathbf{M}, \mathbf{i}+\mathbf{1}}, \mathbf{r}_{\mathbf{M}, \mathbf{i}}$

$$
\mathbf{r}_{\mathbf{M}, \mathbf{i}+\mathbf{1}}=\mathbf{r}_{\mathbf{M}, \mathbf{i}}+\Delta \mathrm{L} \mathbf{e}_{\mathbf{i}}, \quad R_{M, i}=\left|\mathbf{r}_{\mathbf{M}, \mathbf{i}}\right|, \quad R_{M, i+1}=\left|\mathbf{r}_{\mathbf{M}, \mathbf{i}+\mathbf{1}}\right|,
$$

where $R_{M, i}$ and $R_{M, i+1}$ are the length of the cables. The velocity vector of the end-effector is given as

$$
\mathbf{v}_{\mathbf{E}, \mathbf{i}}=\frac{\mathbf{r}_{\mathbf{M}, \mathbf{i}+\mathbf{1}}-\mathbf{r}_{\mathbf{M}, \mathbf{i}}}{\Delta t}=\frac{\Delta L}{\Delta t} \boldsymbol{e}_{\boldsymbol{i}}
$$

The absolute value of the velocity of the end-effector $v_{E \text {,max }}$ is calculated by the substitution of the nominal r.p.m. $n_{\max }$ of the DC motor, the reduction of gear ratio $k$ and the diameter $d$ of the cable reel

$$
\left|\mathbf{v}_{\mathbf{E}, \max }\right|=v_{E, \max }=\frac{\Delta L}{\Delta t}=\frac{n_{\max }}{2 \pi} \frac{60 k d}{2}=\frac{60 n_{\max } k d}{4 \pi},
$$

where $d$ is assumed to be constant since the cables are made of relative very thin rule.

The velocity of the cable driven by motor $\mathrm{M}$, $\mathrm{i}$ is calculated as

$$
\left|\mathbf{v}_{\mathbf{M}, \mathbf{i}}\right|=v_{M, i}=\frac{R_{M, i+1}-R_{M, i}}{\Delta t} .
$$

The DC motors are controlled by pulse width modulation (PWM), the controlling parameter of the motor $\mathrm{M}$, $\mathrm{i}$ is

$$
P W M_{M, i}=\left\{\begin{array}{ll}
255 \frac{v_{M, i}}{v_{E, \text { max }}} ; & \text { if } 255 \frac{v_{M, i}}{v_{E, \max }} \geq 45 \\
45 ; & \text { if } 255 \frac{v_{M, i}}{v_{E, \max }}<45
\end{array}\right\} .
$$


It is noted that the DC motors, which are built into the system, do not rotate if the PWM is smaller than 45 , i.e., they starts to rotate at $P W M=45$, and provide their maximum circular velocity at $P W M=255$.

\section{Structure of the cable robot}

The frame of the cable robot is shown on Figure 2. Four DC motors with gearboxes are mounted at the corners of the rectangle. The end-effector is represented by a blue disc, to which cables are connected.

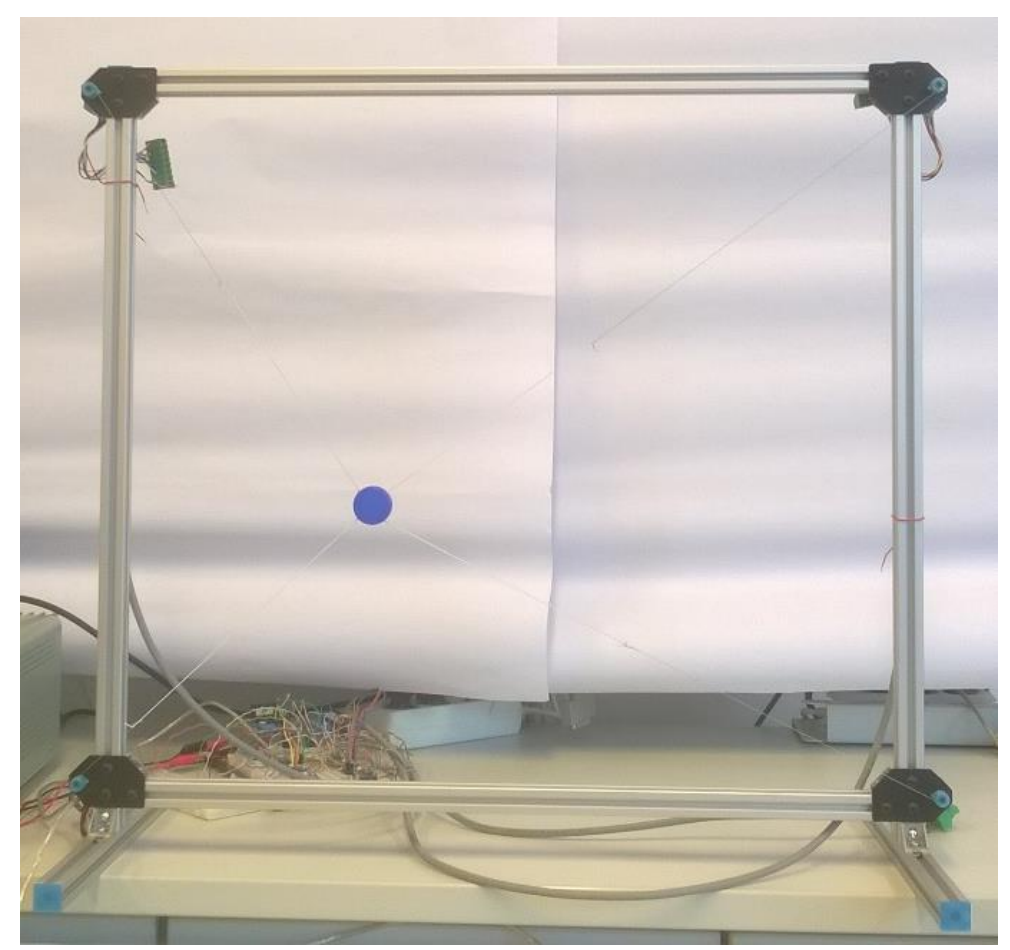

Figure 2. Structure of the cable robot, the end-effector is represented by a blue disk

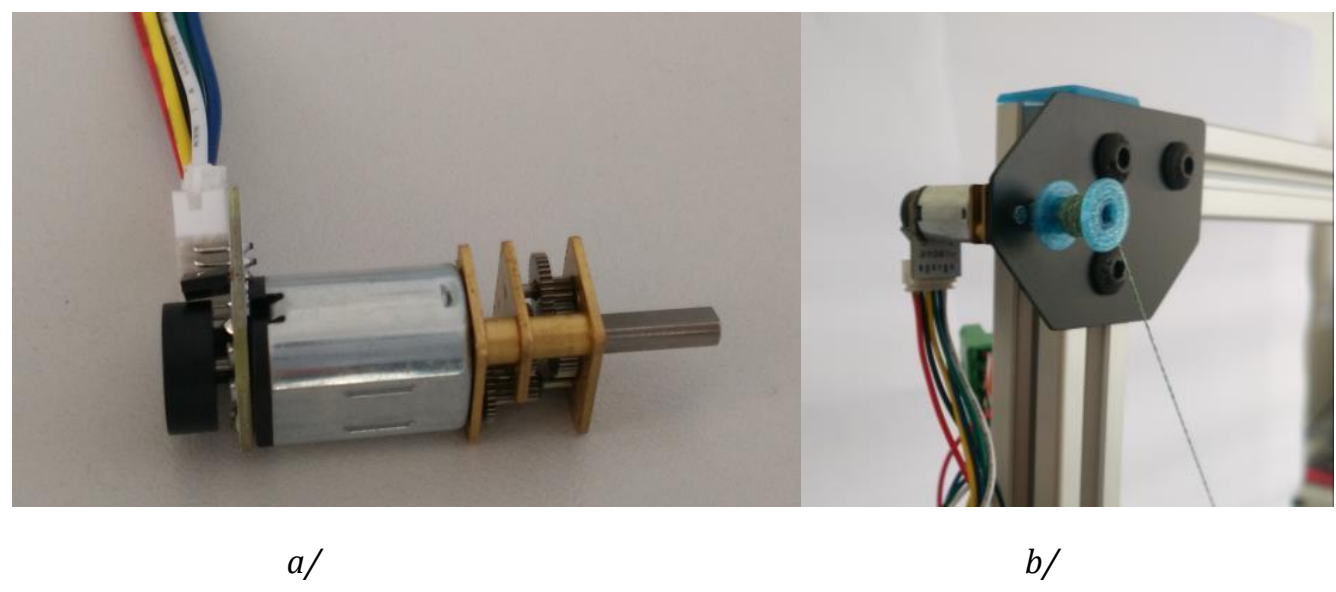

Figure 3. a/ DC motor with gear box; b/ A blue coloured cable reel and thin rule 
A DC motor with Hall sensor and gearbox is shown in Figure 3a, the mounted driving system with blue cable reel is displayed in Figure $3 \mathrm{~b}$. Four DC motors are controlled by four microcontrollers through two H-bridges shown in Figure 4. The fifth microcontroller computes the $P W M_{M, i}$ and the cable length $R_{M, i}$ for each individual motor.

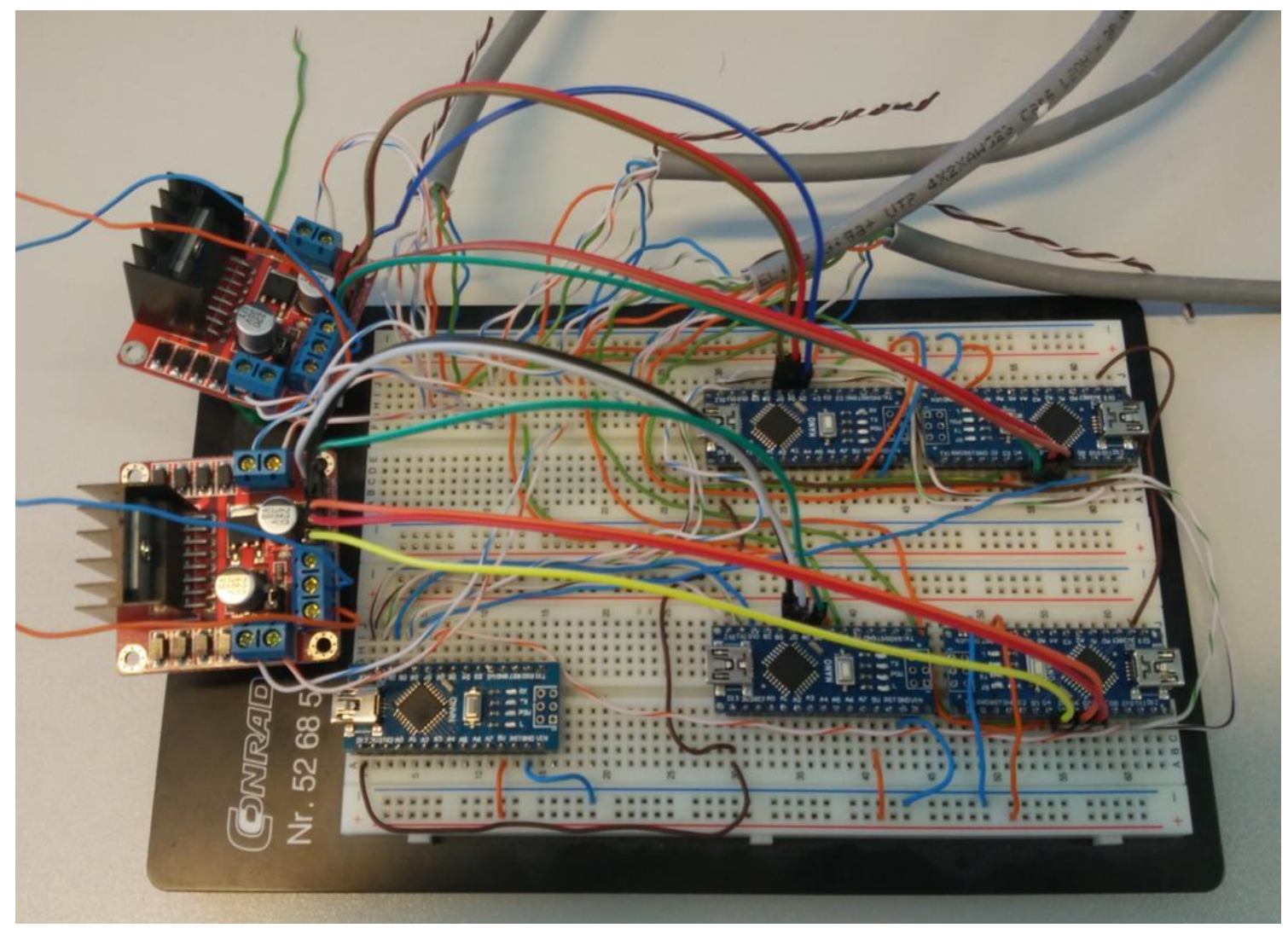

Figure 4. Five microcontrollers and two H-bridges

The fifth microcontroller is the master one the rest of them are regarded as slaves.

\section{Control of the system}

The motion of the end-effector is determined by the use of formulae given in Section 1 and computed by the master microcontroller. The block diagram of the control system is displayed in Figure 5.

To control the robot we decided to use an inexpensive and commercially available microcontroller. We chose the Arduino Nano controller because of the simple development environment. The role of the microcontroller was to calculate the motor coordinates according to the predefined trajectory and control the position and speed of the four DC motor. The feedback from the motors are implemented with incremental rotation encoders. Each motor has an encoder fitted to the axle which generates 7 impulses per revolution. The rated speed of the gearmotor unit is $600 \mathrm{RPM}$, the transmission ratio of the gearbox is 51.45, so the impulse frequency of the encoder at maximum speed is $216090 \mathrm{~Hz}$ for each motor. This is rather high speed to count for a microcontroller, so we decided to implement a parallel architecture shown on Fig. 5. 


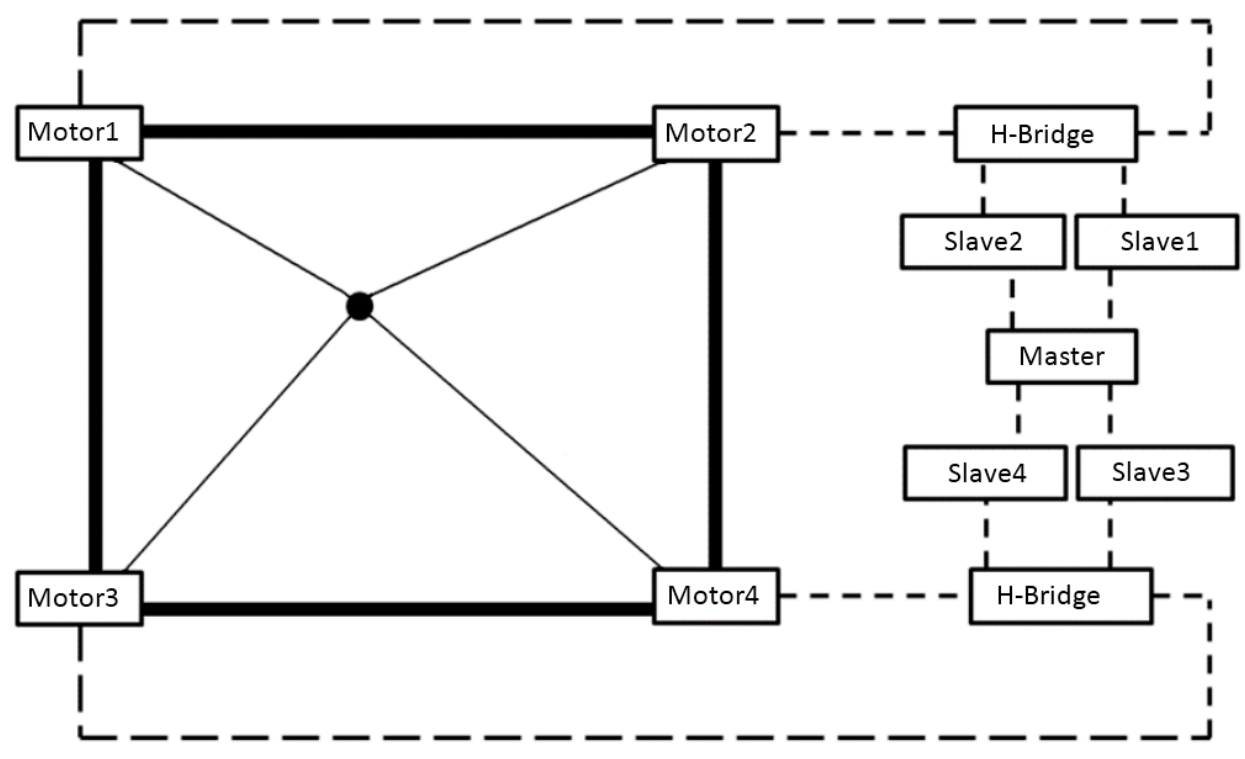

Figure 5. Block diagram of the control system

The task of the "Master" controller is to calculate the desired movements of the four motor and control the "Slave" units to accomplish the movement. The "Slave" controllers are connected to one motor unit each to control its movements according to the command given by the "Master" unit. The "Master" unit and the four "Slave" units are communicating over SPI bus.

The slave units are connected to the quadrature encoder of the corresponding motor and counts the impulses taking into account the direction information. This functionality is implemented in an interrupt service routine, so the main program has an accurate position information of the motor. The main program is relatively simple, it waits for position and speed information from the master controller, controls the motor until the required and the actual positions are equal, and outputs a "ready" signal to the master, which means that the movement is finished, the unit is ready for the next command. The wiring of the controllers, H-bridges and motors are shown on Fig. 6.

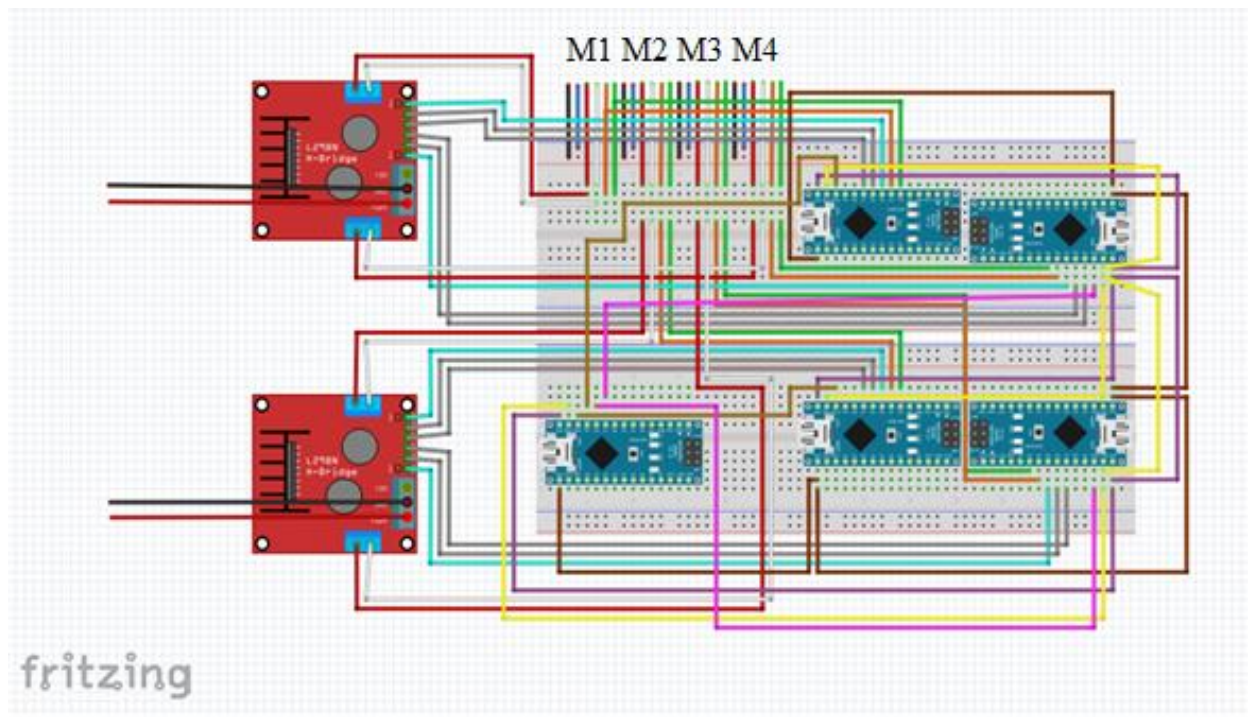

Figure 6. Wiring diagram of the control system 
The motion of the robot is controlled section by section. Motors are started sequentially and stop when they reached to the prescribed angular position determined by number of encoder pulses. It means that the motors are not stopped in different times. When each motor is in the appropriate position a new section is initiated.

In order to demonstrate the implemented method two examples are given in the sequel. In the first example the end-effector performs a circle path shown in Figure 7. The cable lengths $R_{M, i}$ and the speed control of the motors $P W M_{M, i}$ are shown in Figure 8a and Figure 8b, respectively.

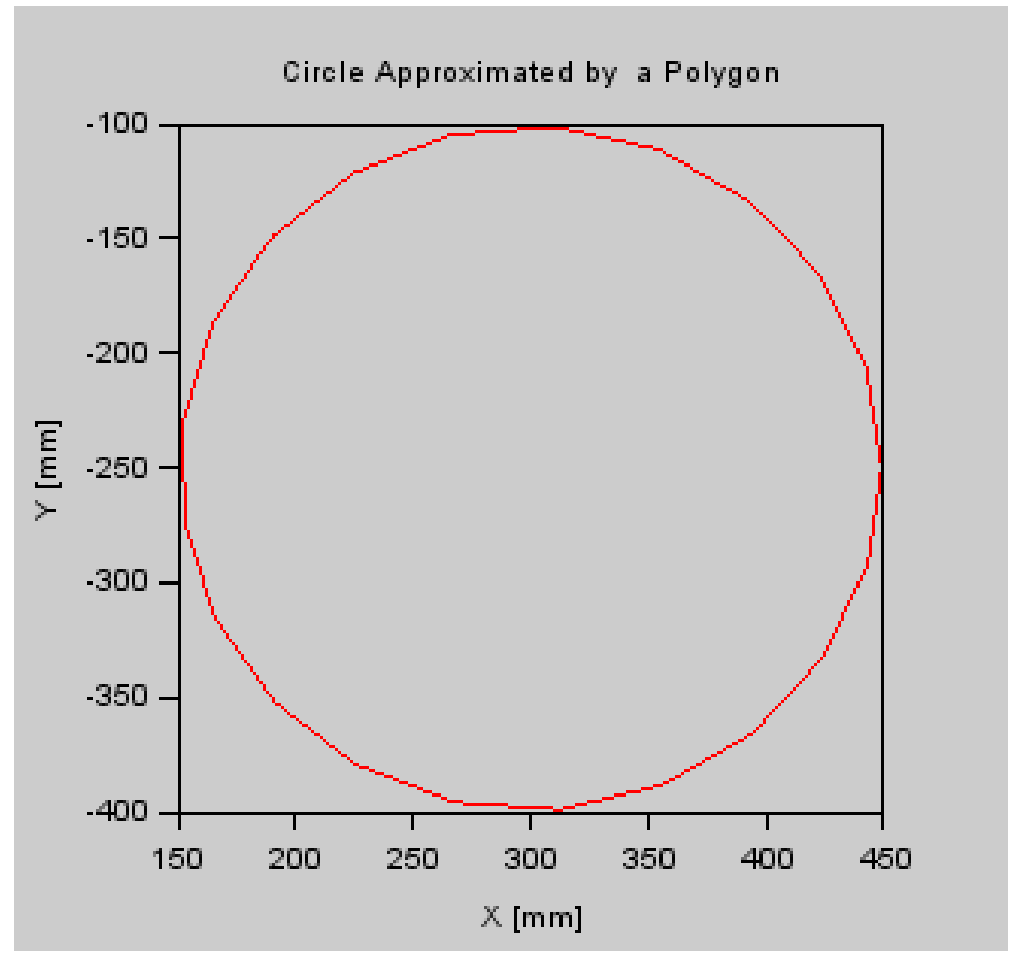

Figure 7. Circle path of the end-effector

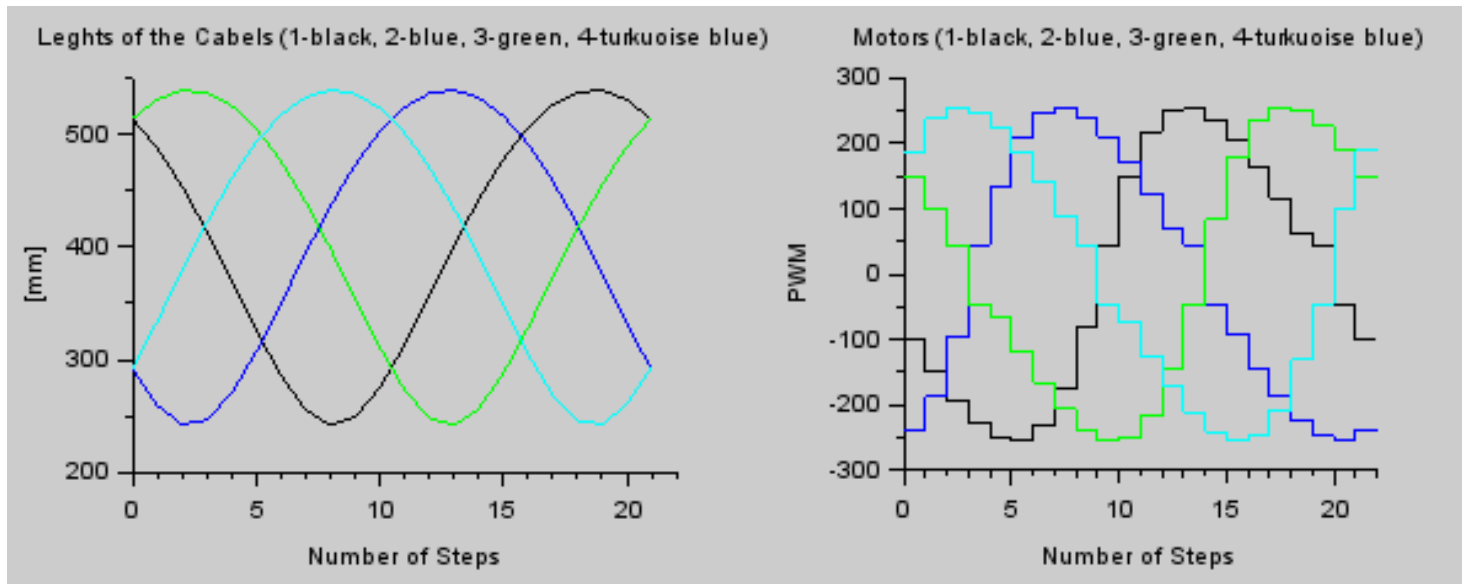

a)

b/

Figure 8. a/ Cable lengths $R_{M, i} ;$ b/ Pulse Width Modulation ( $P W M_{M, i}$ ) 
The second example demonstrate the rectangle motion of the end-effector in Figure 9. The cable lengths $R_{M, i}$ and the speed control of the motors $P W M_{M, i}$ are shown in Figure 10a and Figure 10b, respectively.

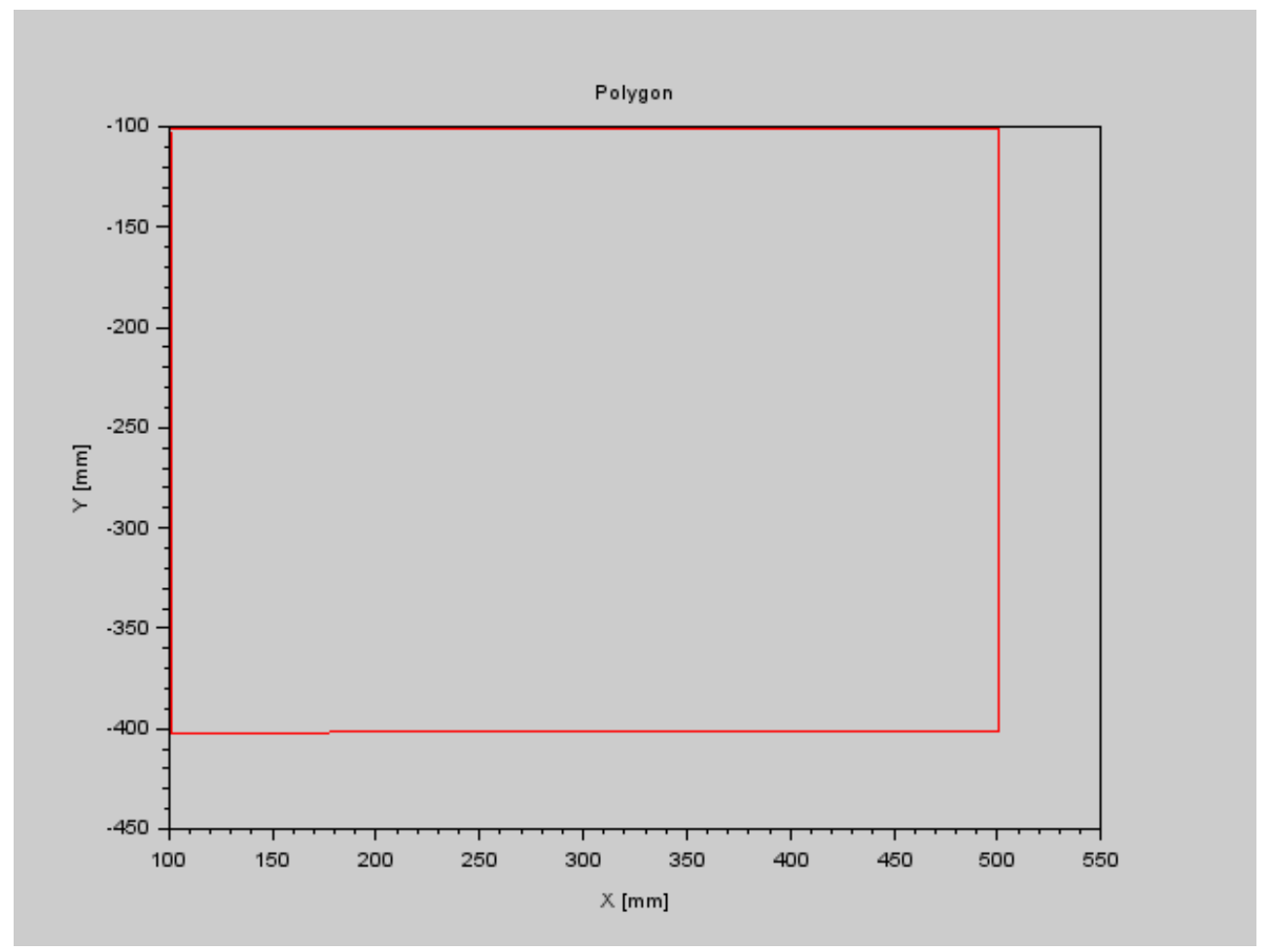

Figure 9. Rectangle path of the end-effector

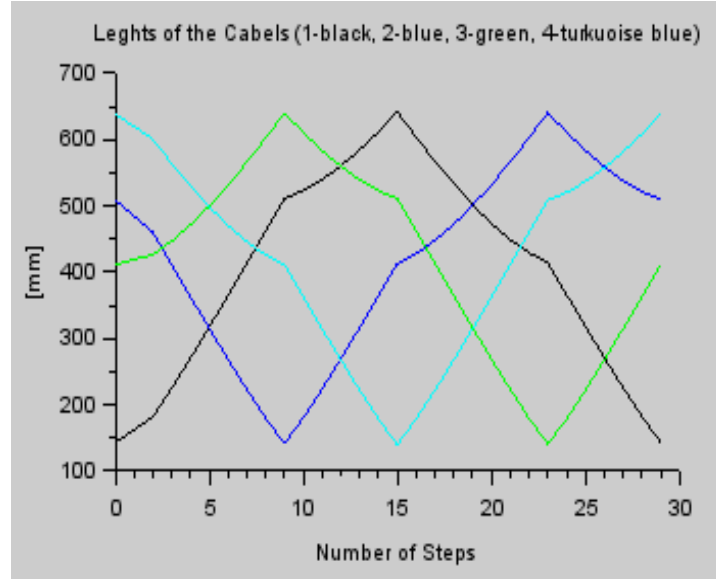

a)

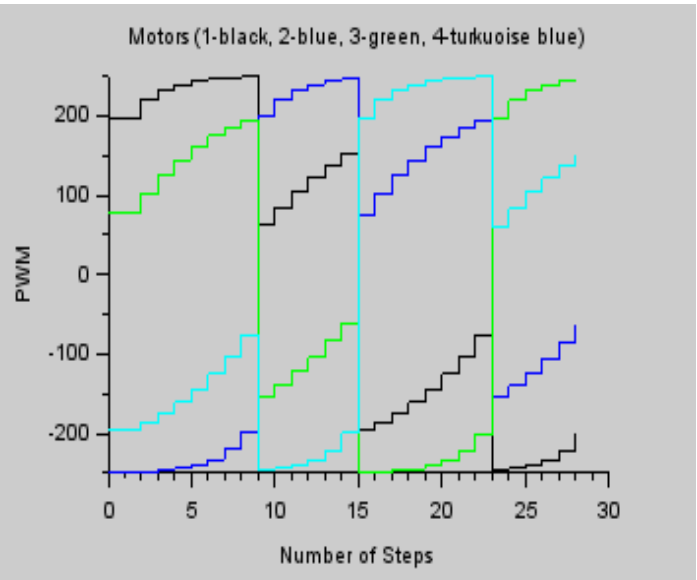

b/

Figure 10. a/ Cable lengths $R_{M, i} ; \quad$ b/ Pulse Width Modulation ( $P W M_{M, i}$ )

\section{Summary and conclusions}

An experimental 2D cable robot has been developed with low budget elements. Kinematic equations of the robot has been formulated assuming constant absolute velocity for the end-effector. The motion of the testbench is controlled by section and section of a polygon. It means that movement is 
discontinuous. However the performed path is accurate enough at least at the corner points of the polygon.

Further development of the system is planned by using signal tracking method, which would provide smooth motion but less accurate path realization. In this case the reference signal would be the time function of the cable lengths, the feedback is the actual length of the cable determined by the angular position of the motor. The planned compensator is a PID controller.

Acknowledgments. The described article was carried out as part of the EFOP-3.6.1-16-2016-00011 "Younger and Renewing University - Innovative Knowledge City - institutional development of the University of Miskolc aiming at intelligent specialisation" project implemented in the framework of the Szechenyi 2020 program. The realization of this project is supported by the European Union, cofinanced by the European Social Fund.

\section{References}

[1] T. Bruckmann - W. Lalo - C. Sturm (2013) Application examples of wire robots, In: Multibody System Dynamics, Robotics and Control / Workshop on Multibody System Dynamics, Robotics and Control ; Linz, 26.-27.09.2011 / Gattringer, Hubert; Gerstmayr, Johannes; (Hrsg.), pp. 291310.

[2] P. Tempel - F. Schnelle - A. Pott - P. Eberhard (2015)Design and Programming for Cable-Driven Parallel Robots in the German Pavilion at the EXPO 2015. Machines. 3. pp. 223-241.

[3] XJ. Jin - IK. Jun - A. Pott - S. Park - JO. Park - SY. Ko (2013) Four-cable-driven parallel robot. 2013 13th International Conference on Control, Automation and Systems (ICCAS 2013), pp. 879-883.

[4] M. H. Korayem - H. Tourajizadeh - M. Jalali - F. Omidi (2012) Optimal Path Planning of Spatial Cable Robot Using Optimal Sliding Mode Control. International Journal of Advanced Robotic Systems. 9. 168. DOI: 10.5772/52892

[5] J. J. Gorman - K. W. Jablokow - D. J. Cannon (2001) The Cable Array Robot: Theory and Experiment. Proceedings 2001 ICRA. IEEE International Conference on Robotics and Automation, 21-26 May 2001, DOI: 10.1109/ROBOT.2001.933047

[6] K. S. Jadhao - P. Lambert - T. Bruckmann - J. L. Herder (2018) Design and Analysis of a Novel Cable-Driven Haptic Master Device for Planar Grasping. In: Gosselin C., Cardou P., Bruckmann T., Pott A. (eds) Cable-Driven Parallel Robots. Mechanisms and Machine Science, vol 53. Springer, Cham.

[7] T. Bruckmann - A. Pott - D. Franitza - M. Hiller (2006) A Modular Controller for Redundantly Actuated Tendon-Based Stewart Platforms. Proceedings of EuCoMeS, the first European Conference on Mechanism Science Obergurgl (Austria), February 21-26 2006. 